\title{
Pemanfaatan Digital Marketing Sistem E-commerce sebagai Media Promosi
}

\author{
Sarwindah $^{\mathrm{a} 1}$, Marini ${ }^{\mathrm{b} 2}$, Anisah ${ }^{\mathrm{b} 3}$, Yurindra $^{\mathrm{b} 4}$ \\ a Program Studi Bisnis Digital Fakultas Ekonomi Bisnis, ISB Atma Luhur \\ ${ }^{1}$ indah_syifadatmaluhur.ac.id \\ ${ }^{b}$ Program Studi Sistem Informasi Fakultas Teknologi Informatika, ISB Atma Luhur \\ 2arinimarini44@atmaluhur.ac.id \\ 3anisaheatmaluhur.ac.id \\ ${ }^{4}$ yurindra@atmaluhur.ac.id
}

\begin{abstract}
Abstrak
Eka Collection merupakan sebuah usaha bisnis yang bergerak di bidang penjualan berbagai jenis pakaian muslimah dan anak-anak dengan tujuan untuk memudahkan masyarakat sekitar untuk mencari pakaian muslimah dewasa maupun anak-anak dan banyaknya pesaing bisnis yang bergerak di bidang yang sama di wilayah tersebut. Seiring berjalannya waktu, munculnya beberapa pesaing sejenis yang menjadi daya tarik bagi Eka Collection untuk mengembangkan usahanya dengan cara mempromisikan mengganakan Digital Mareketing seperti Facebook, Instagram dan lain-lain, Permasalahan pada Eka Collections yaitu kegiatan penjualan seperti mempromosikan informasi masih dilakukan secara manual dengan melakukan pencatatan data barang penjualan sehingga rentan akan hilangnya data. Untuk mengatasi masalah pada Eka Collections perlu adanya suatu sistem informasi berbasis e-commerce untuk memudahkan proses penjualan baik di bidang pemasarannya maupun pengolahan datanya. Dalam penelitian ini, peneliti menggunakan model FAST (Framework the Application Of System Thinking) yang hanya menggunakan 5 tahap yaitu analisa kebutuhan, spesifikasi, perancangan, implementasi dan pemeliharaan. Dengan adanya sistem informasi berbasis e-commerce pada Eka Collections dapat memudahkan pelanggan untuk melakukan pembelian barang karena semua barang sudah disediakan secara online dan juga memudahkan dalam pengelolaan data yaitu data dapat di backup untuk mencegah kehilangan data.
\end{abstract}

\section{Utilization of E-commerce Digital Marketing System as a Promotional Media}

\begin{abstract}
Eka Collection is a business that is engaged in the sale of various types of Muslim and children's clothing to make it easier for the surrounding community to find Muslim clothing for both adults and children and the number of business competitors engaged in the same field in the region. Over time, several similar competitors emerged which became the main attraction for Eka Collection To develop its business by promoting digital marketing such as Facebook, Instagram, and others, the problem with Eka Collections is that sales activities such as promoting information are still carried out manually by recording data on sales items so they are vulnerable to data loss. To solve the problem with Eka Collections, it is necessary to have an e-commerce-based information system to facilitate the sales process, both in marketing and data processing. In this study, researchers used the FAST (Framework the Application Of System Thinking) model which only used 5 stages, namely needs analysis, specification, design, implementation, and maintenance. With the existence of an e-commerce-based information system in Eka Collections, it can make it easier for customers to purchase goods because all goods have been provided online and also makes it easier to manage data, namely data can be backed up to prevent data loss.
\end{abstract}

Keywords: Digital Marketing, E-Commerce, Promotion

I. Pendahuluan

Dengan banyaknya persaingan diantara dunia bisnis maka teknologi informasi semakin dibutuhkan untuk kelancaran bisnis. Teknologi informasi ini 
diimplementasikan dalam komputer sehingga yang tadinya kegiatan dilakukan secara manual sekarang sudah terkomputerisasi. Sekarang penjualan online sudah meyebarluas dikalangan masyarakat. Penjualan online dilakukan melalui berbagai media sosial seperti facebook, instagram dan media sosial lainnya. Namun juga ada sebuah website yang dirancang khusus untuk penjualan online yaitu e-commerce. Berdasarkan latar belakang dari permasalahan yang ada pada eka collections peneliti ingin merancang suatu sistem berbasis e-commerce untuk memudahkan dalam promosi dan memasarkan produk kepada pelanggan secara online dan menyediakan informasi tentang produk yang ada di Eka Collections. Adapun tujuan dari penelitian ini adalah membantu Eka Collections untuk melakukan promosi dan memasarkan produk kepada konsumen, memudahkan konsumen melakukan pemesanan secara online dan memberikan kemudahan dalam melakukan transaksi.

\section{A. Penelitihan Terdahulu}

Untuk melakukan pemodelan sistem / perangkat lunak secara visual digunakan UML (Unified. Modelling Language) yang digambarkan secara elektronik kombinasi dari teknologi informasi dan aktivitas orang yang menggunakan teknologi itu untuk mendukung operasi dan manajemen.[1], Dengan menggunakan model diharapkan pengembangan piranti lunak dapat memenuhi semua kebutuhan pengguna dengan lengkap dan tepat, termasuk faktor-faktor seperti scalability, robustnees, security, dan sebagainya. Untuk melakukan pemodelan sistem / perangkat lunak secara visual digunakan UML (Unified Modelling Language) yang digambarkan secara elektronik lewat sarana perangkat lunak Rational Rose [2], Unified Modelling Language (UML) merupakan bahasa pemodelan perangkat lunak atau sistem dengan konsep pemrograman berorientasi objek yang dapat analisa dan menjabarkan secara rinci apa yang diperlukan oleh sistem.[3], sebuah program aplikasi atau software yang merequest dokumendokumen dari komputer-komputer yang terkoneksi dengan internet.[4], Merancang Database merupakan persiapan program.[5], Dalam menghasilkan sebuah situs dinamis, PHP digunakan bersama-sama dengan relational-database management-system (RDBMS) untuk tempat penyimpanan data, seperti MySQL. MySQL adalah RDMS open source yang paling populer saat ini, selain memiliki fitur database yang lengkap, multi user dan sangat cepat. MySQL sangat umum dipakai untuk aplikasi berbasis web.[6], penelitian yang digunakan dalam penelitian ini bersifat deskriptif analisis, dan dilakukan melalui tahapan system development yang menggunakan metode pengembangan FAST (Frame Work for the Application of System Technique) dan teknik pengembangan JAD (Joint Application Development) mengikuti tahapan-tahapan Sistem Life Cycle dengan tambahan alat-alat dan teknik yang disediakan untuk memudahkan analis dalam pelaksanaan pengembangan sistem, sehingga hasil akhir dari sistem yang dikembangkan akan mendapatkan sistem yang terstruktur dan didefinisikan dengan baik dan jelas.[10], Aplikasi web yang dibuat memberikan informasi mengenai perjalanan barang dari daerah yang satu ke daerah yang lain sehingga pihak penyedia layanan atau pemilik barang dapat menggunakan informasi tersebut (tracking), memuat berbagai informasi pengiriman terkini, memuat informasi tarif, memuat profile dan memberikan informasi lain yang berguna bagi pelanggan.[7], Penerapan Sistem Informasi E-Commerce Berbasis Web (Studi Kasus Untuk Vendor Pernikahan).[8], Perancangan Sistem Informasi Penjualan Berbasis E-Commerce Studi Kasus Toko Kun Jakarta.[9], Perancangan Web E-Commerce Pada Toko Helmet Fullface.[10], Implementasi Metode Rapid Application Development Dalam Membangun ECommerce di Bidang UKM.[11], Analisis dan Perancangan Sistem Informasi E-Commerce Berbasis Web Pada UMKM Batik Rindani Jambi.[12].

\section{METODOLOGI}

Dalam penelitian ini, penulis membuatkan kerangka kerja penelitian seperti pada Gambar 1 berikut ini.

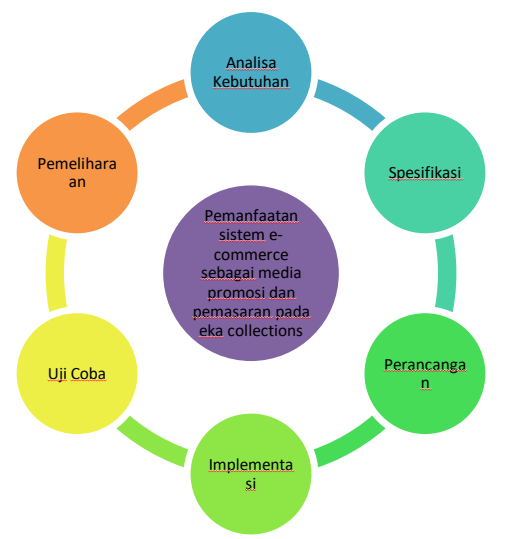

Gambar 1. Kerangka Kerja Penelitian

Tahapan Pembangunan Sistem yakni:

1) Analisa Kebutuhan Sistem Tahap menganalisis data yang telah dikumpulkan merupakan tahap analisis berkaitan dengan proses dan data yang dibutuhkan oleh sistem. Analisis harus mencakup kebutuhan pengguna, interface, dan fungsi yang dibutuhkan. Hasil analisa yaitu berupa model sistem yang telah terstruktur.

2) Perancangan Sistem Berdasarkan kebutuhan sistem yang telah dianalisis maka dilakukan perancangan system.

3) Implementasi Sistem Implementasi sistem pada tahap ini, peneliti berfokus pada penerapan pemanfaatan sistem.

4) Pengujian dan Analisis Pengujian dilakukan terhadap sistem yang telah dibangun. Pengujian ini bertujuan untuk membuktikan konsep dan sesuai kebutuhan pengguna.

5) Penarikan Kesimpulan Penarikan Kesimpulan dilakukan berdasarkan hasil analisa dan pengujian yang telah dilakukan, apakah hasil dari perancangan sistem dapat menjawab pertanyaan pada rumusan masalah dan sesuai dengan hipotesis serta kebutuhan pengguna. 


\section{HASIL DAN PEMBAHASAN}

\section{A. Analisa Kebutuhan}

Sistem Tahap menganalisis berkaitan dengan proses dan data yang dibutuhkan oleh sistem. Analisis harus mencakup kebutuhan pengguna, interface, dan fungsi yang dibutuhkan. Fase ini akan menguraikan mengenai proses bisnis yang digambarkan dalam bentuk activity diagram. 1. Activity Diagram Pencatatan Data Penjualan

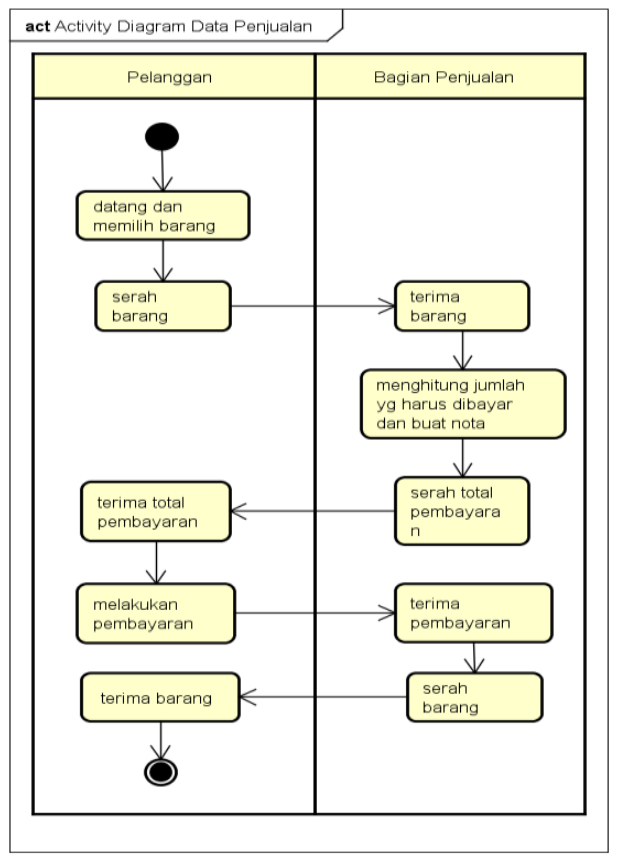

Gambar 2. Activity Diagram

Pencatatan Data Penjualan yang menggambarkan proses bisnis yang berjalan pada eka collection

\section{B. Perancangan Sistem}

Berdasarkan kebutuhan sistem yang telah dianalisis maka dilakukan perancangan system.

\section{1) Logical Record Structure ( LRS )}

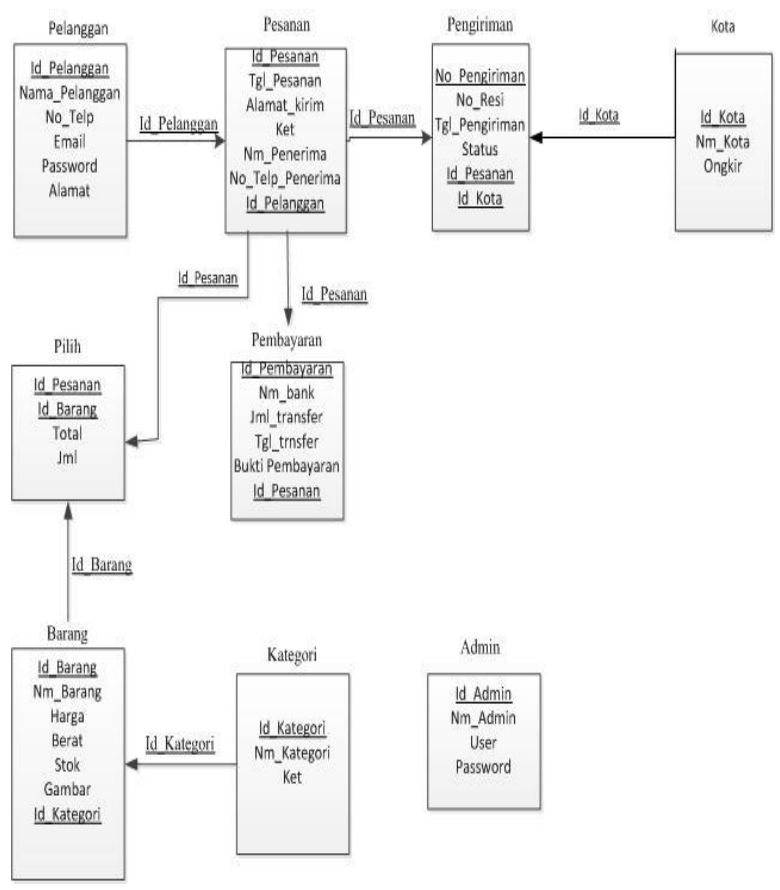

Gambar 3. Logical Record Struktrur (LRS)

Menjelaskan basis data dari hasil analisa keutuhan yang terdapat delapan table.

C. Implementasi Sistem:

Implementasi sistem pada tahap ini, peneliti berfokus pada pemanfaatan system berbasis web.

1) Tampilan Layar

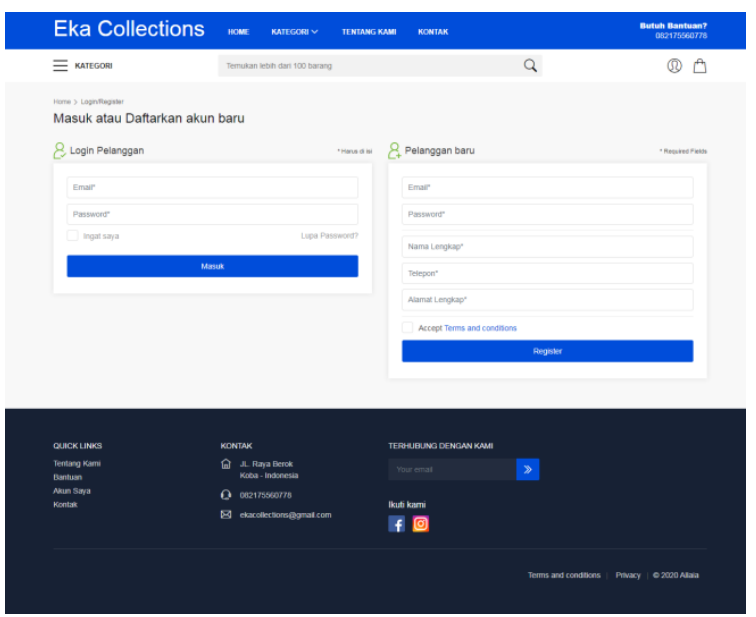

Gambar 4. Tampilan Layar Login

Tampilan layar login merupakan halaman yang dapat diakses pengguna untuk masuk ke system dan bagi pengguna yang baru daftar. 


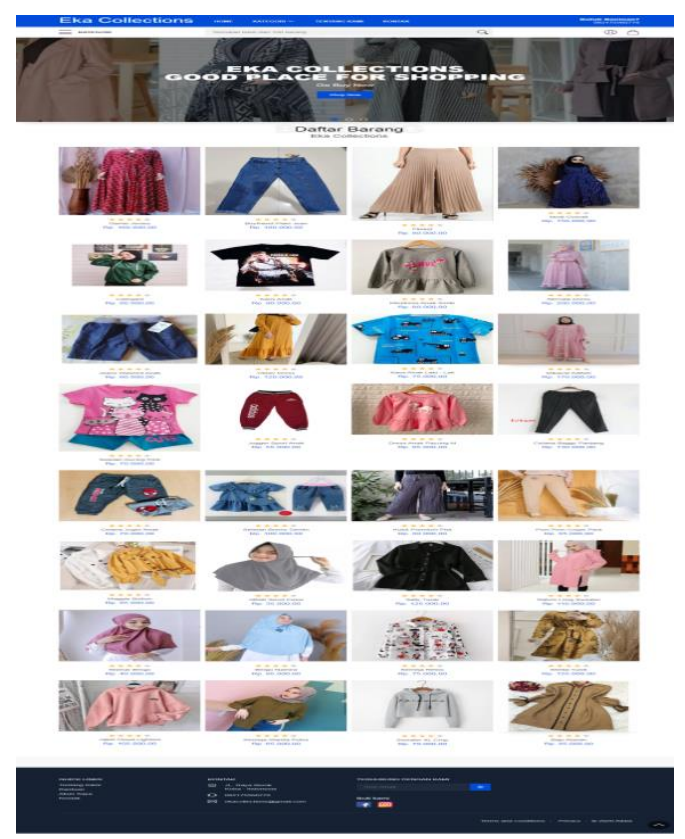

Gambar 5. Tampilan Layar Galery

Tampilan layar Galery merupakan halaman yang berisikan produk yang di jual pada toko Eka Collection.

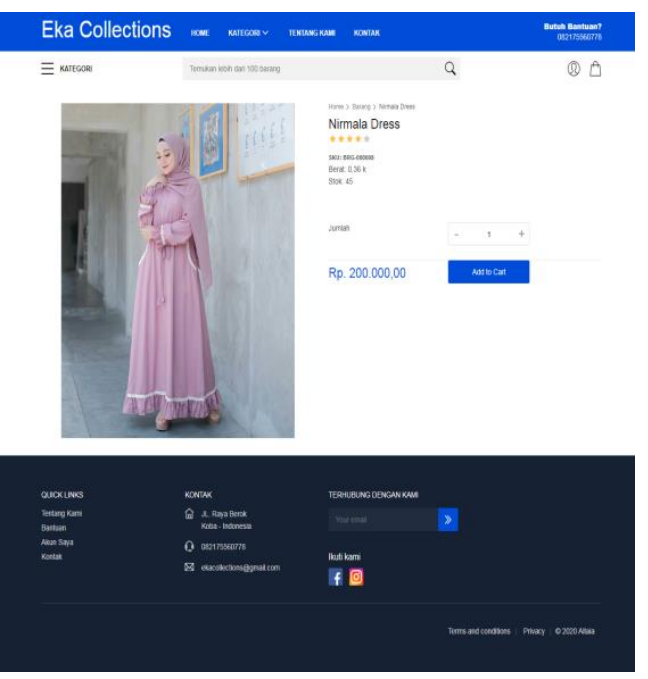

Gambar 6. Tampilan Layar Kategori

Tampilan layar Kategori merupakan halaman yang berisikan produk yang di jual pada toko Eka Collection yang menjadi salah satu promosi.

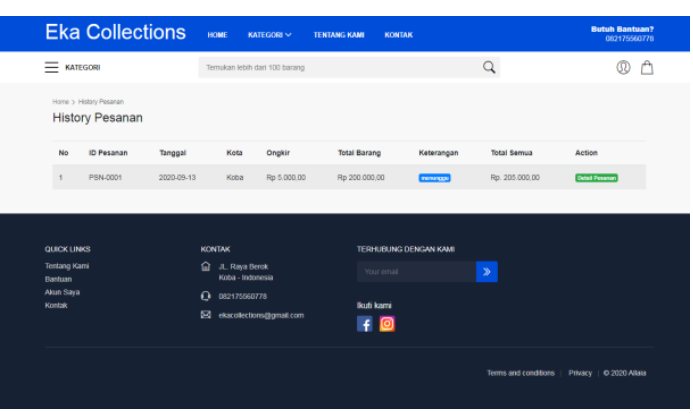

Gambar 7. Tampilan Layar Pemesanan

Tampilan layar pemesanan merupakan halaman yang berisikan produk yang di pesan pada toko Eka Collection.

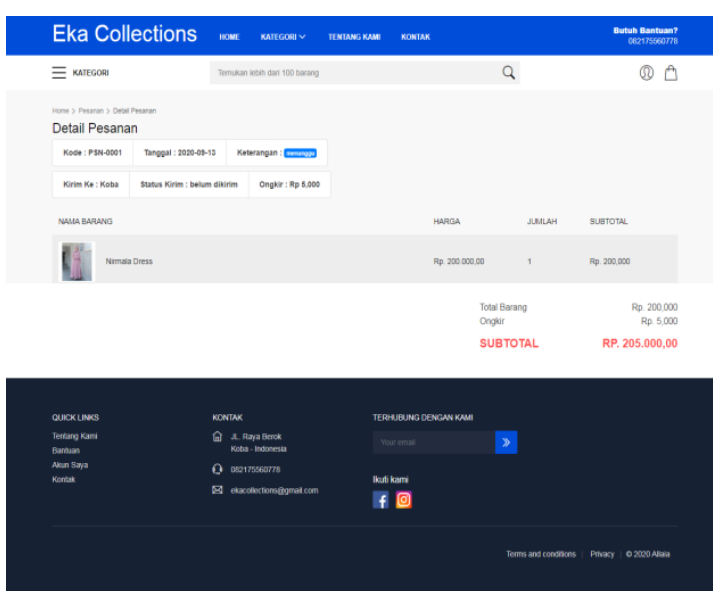

Gambar 8. Tampilan Layar keranjang Pemesanan

Tampilan layar kerancang pemesanan merupakan halaman yang berisikan produk yang di pesan dan detail pemesanan pada toko Eka Collection.

\section{KESIMPULAN}

Berdasarkan kesimpulan hasil dari Pemanfaatan Digital Marketing system e-commerce sebagai media promosi pada eka collections maka dapat disimpulkan bahwasanya dengan adanya $e$-commerce sebagai salah satu media yang bisa dimanfaatkan sebagai sarana promosi dan pelanggan pada Eka Collections mudah dalam melakukan pembelian barang tanpa harus datang ketoko karena sudah dilakukan secara online. Website e-commerce ini juga memudahkan karyawan toko dalam melakukan pengolahan data dan mempromosikan barang yang di jual pada toko karena sudah terkomputerisasi sehingga dalam pemanfaatan website e-commerce dapat memberikan perkembangan informasi, promosi dan penjualan pada Eka Collections lebih efektif sesuai perkembangan zaman.

\section{DAFTAR PUSTAKA}

[1] Sutabri, Tata. Analisa Sistem Informasi. Jakarta : Penerbit Andi, 2012

[2] Suhendra, dan Hariman Gunadi. Visual Modelling Menggunakan UML dan Rational Rose. Bandung : Informatika, 2009.

[3] Munawar, Pemodelan UML Berorientasi Objek. Jakarta : Andy Jogyakarta, 2007

[4] F. K. S. Alexander. Kitab Suci Web Programming, MediaKom, Yogyakarta. 2011

[5] N. Bunafit, Dasar Pemrograman Web PHP - MySQL Dengan Dreamweaver, GavaMedia, Yogyakarta, 2013.

[6] M. R.. Arief, Pemrograman Web Dinamis Menggunakan PHP dan MySQL, CV Andi, Yogyakarta, 2011.

[7] S. Sarwindah, "Sistem Pendaftaran Siswa Baru Pada SMP N 1 Kelapa Berbasis Web Menggunakan Model UML,” J. Sisfokom (Sistem Inf. dan Komputer), vol. 7, no. 2, p. 110, 2018, doi 10.32736/sisfokom.v7i2.573.

[8] Trianto, Eka \& Revina, Widya. Perancangan Sistem Iinformas Pencatatan Pengiriman Barang di PT. TIKI Jalur Nugraha Ekakurir Cabang Bandung. Diakses pada 27 Febuari 2016.

[9] S. Handayani, "Perancangan Sistem Informasi Penjualan Berbasis E-Commerce Studi Kasus Toko Kun Jakarta,” J. Ilk. Vol. 10 No 2 Agustus 2018, vol. 10, pp. 182-189, 2018.

[10] I. P. M. Ika Yuniva, Andriansah, "Perancangan Web E-Commerce Pada Toko Helmet Fullface," Inti Nusa Mandiri Vol. 13. NO. 2 Februari 2019 ISSN 0216-6933, vol. 13, no. 2, pp. 9-14, 2019.

[11] V. Riyanto, "Implementasi Metode Rapid Application Development Dalam Membangun E-Commerce DiBidang UKM," 
J. Pilar Nusa Mandiri Vol. 13 N0.1, Maret 2017, vol. 13, no. 1, pp. 122-127, 2017.

[12] D. S. dan Lutfi, "Analisis dan Perancangan Sistem Informasi ECommerce Berbasis Web Pada UMKM Batik Rindani Jambi," J. Sains Sosio Hum. Vol. 2 Nomor 1 Januari-Juni 2018, vol. 2, pp. 69-78, 2018.

[13] S. Sarwindah, "Prototype Sistem Pembiayaan Berbasis MFINWEB pada PT. Mandala Finance," J. Justin (Jurnal Sistem Informasi dan Teknologi Informasi), vol. 8, no. 4, p. $322-327$, 2020, DOI: 10.26418/justin.v8i4.41522

[14] S. Sofian, "Penerapan Sistem Informasi E-Commerce Berbasis Web (Studi Kasus Untuk Vendor Pernikahan)," JITEKH, Vol 6, No 2, Tahun 2017, 52-57, vol. 6, no. 2, pp. 52-57, 2017.

[15] Wahyuningrum, Tenia dan Januarita, Dwi, 2014, "Perancangan WEB e-Commerce dengan Metode Rapid Application Development (RAD) untuk Produk Unggulan Desa", Seminar Teknologi Informasi dan Komunikasi Terapan (Semantik), Semarang.

[16] Agung Wahana,Irvan Purliansya. 2012. Pembangunan ECommerce (Penjualan Online) Pada Turpez Shop. Jurnal Computech \& Bisnis, , No. 1, Vol. 6, 27-33

[17] Ricky, R. 2016. Rancang Bangun E-Commerce pada Toko Madu Sport. Jurnal Nuansa Inormatika, No.1, Vol.11, 1858-3911.

[18] Tony, W. dan Donny, P. 2014. Rancang Bangun Website ECommerce pada Barcelona Sport. Jurnal Ilmiah Sisfotenika, No.1, Vol.4 